\title{
Study on Modified Sand Filtration Towards Water Quality of Wet Market Waste Water
}

\author{
F.N.M. Saad ${ }^{1, *}$, M.N. Jamil ${ }^{1}$, Z.S.M. Odli ${ }^{1}$, and T.N.T. Izhar $^{1}$ \\ ${ }^{1}$ School of Environmental Engineering, Universiti Malaysia Perlis (UniMAP), Kompleks Pusat \\ Pengajian Jejawi 3, 02600 Arau, Perlis, Malaysia.
}

\begin{abstract}
Investigation on the potential of sand filter as a pre-treatment of waste water was done in Kangar wet market, Perlis. Besides, the best composition of filter in order to treat wastewater based on BOD, COD, $\mathrm{SS}, \mathrm{AN}$, turbidity and $\mathrm{pH}$ levels are further examined. In this study, there are four types of sand filter composition which the medias consist of fine sand and coarse sand while the modified sand filter are consist of sand, course sand and activated carbon prepared from rice husk and coconut shells. After 10 weeks of treatment, the results show that the concentration of BOD, COD, SS, AN, turbidity and $\mathrm{pH}$ were reduced up to $86 \%, 84 \%$, $63 \%, 88 \%, 73 \%$, respectively while $\mathrm{pH}$ nearly to neutral with 6.83 . Moreover, the result also revealed that the sand filter added with rice husk almost complied with Standard B of Malaysia Environmental Quality (Sewage) Regulations 2009 as well as gives the highest number of WQI with 36.81. Overall, WQI obtained in this study are ranged from 12.77 to 36.81 .
\end{abstract}

\section{Introduction}

Wet market is the place where people get raw materials such as fish, vegetables and chicken. Waste water generated from this premise is from different sources and activities such as cleaning of fish, vegetables and fruits as well as slaughtering poultry which used huge water usage. Then, this waste water containing high organic and inorganic matters are directly discharged into the drains without any treatment.

As said by Idris et al. [1], the wet market waste water usually contains two to three times of organic matter and solids commonly found in residential waste water, thus waste water, produce from market sources classified as "high intensity". Discharged of untreated waste water adds oxygen-demanding substances, nutrients and toxic elements into the water, thus influencing the level of parameters such as BOD, COD and TSS in the receiving water. This scenario in turn converts the streams to become unsuitable for aquatic flora and fauna. Because of this effect, discharged of grey water into the steam need to be treated to avoid or reduce that effect [1]. Therefore, an economical and easy to be used treatment should be applied in the premise in order to treat the waste water generated from wet market before it being released to receiving water.

\footnotetext{
*Corresponding author: farahnaemah@unimap.edu.my
} 
Sand filter is one of the oldest wastewater treatment technologies. It is also a biofilm technology that has been used in waste water treatment due to its low cost and maintenance and relatively high treatment efficiency. There have been several studies carried out and reported relevant to the application of sand filter in treating waste water [2,3]. Results showed that the sand filter may reduce the concentration of water quality such as BOD, COD and SS. Therefore, this study is aimed to observe the potential of sand filter act as a pre-treatment of wet market waste water as well as to compare the quality of waste water produced from conventional sand filter with modified sand filter which added with activated carbon based on BOD,COD, suspended solid, AN, turbidity and $\mathrm{pH}$.

\section{Materials and methods}

\subsection{Sampling location and activity}

Kangar wet market $\left(6^{\circ} 26^{\prime} 11^{\prime \prime} \mathrm{N} 100^{\circ} 11^{\prime} 33^{\prime \prime} \mathrm{E}\right)$ was chosen as sampling location. Grab water sample was collected at the final discharge of the wet market during peak hour of wet market operation before being transfered to the laboratory for further study.

\subsection{Preparation of activated carbon}

Coconut shell was taken from the local shop selling coconut milk while the rice husk was collected from local rice mill. Both materials were washed with distilled water to remove impurities before being dried in the oven. Then, both coconut shell and rice husk were burned in the furnace at $300^{\circ} \mathrm{C}$ for 2 hours before being ground and sieved according to the desired size.

\subsection{Preparation of sand filter}

The sand filtrations were constructed in the transparent plastic columns. The dimension of each plastic column is $260 \mathrm{~mm}$ of height, $80 \mathrm{~mm}$ for top diameter and $24 \mathrm{~mm}$ for bottom diameter. A hole was created at the bottom of the plastic column which acts as a channel for effluent water sample.

Fine sand, coarse sand, as well as rice husk and coconut shell act as activated carbon, with their effective size of $0.06 \mathrm{~mm}, 2.00 \mathrm{~mm}$, and $0.08 \mathrm{~mm}$, respectively were used in this study. All these materials were washed by using distilled water to remove impurities and dried before being filled up in the plastic column. Plastic net was used to avoid the material from wash out.

There were four types of sand filtrations used in this study. There were sand filtration consist only fine and course sand, sand filtration with additional of rice husk, sand filtration with additional of coconut shell and sand filtration with additional of rice husk and coconut shell. The schematic diagram of all sand filters used in this study is shown in Fig. 1.

\subsection{Experimental study}

$5 \mathrm{~L}$ of water sample was pumped into each of the sand filter. The flow rate for all filters was $0.13 \mathrm{~L} / \mathrm{min}$. Then, the effluent of each sand filter was collected for further analysis. In this study, six parameters were chosen based on water quality index (WQI). The parameters are $\mathrm{BOD}, \mathrm{COD}, \mathrm{SS}$, ammoniacal nitrogen, $\mathrm{pH}$ and turbidity. All procedures of experiments were according to American Public Health Association (APHA) [4]. 


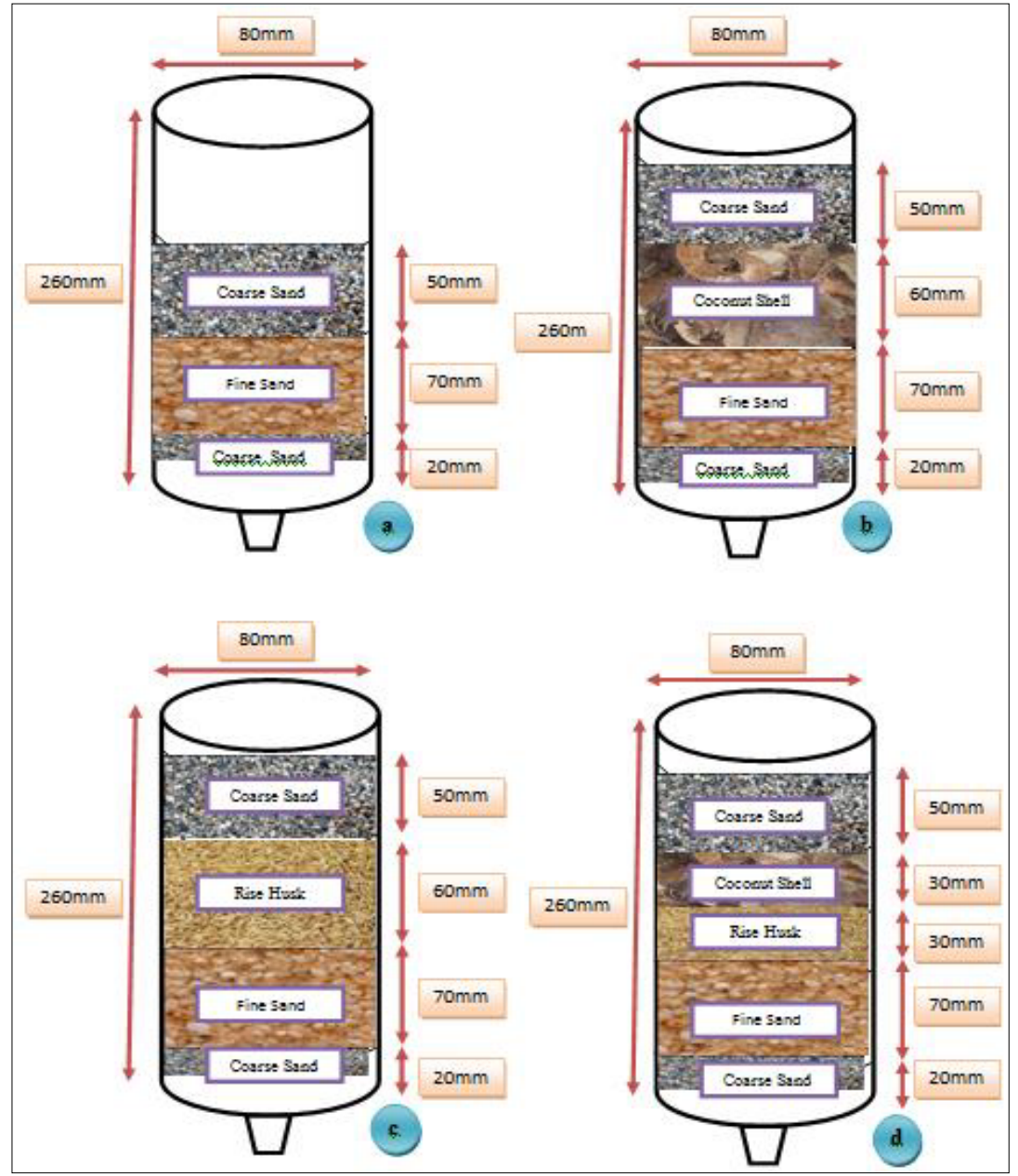

Fig. 1. Schematic diagram of (a) sand filtration, (b) sand filtration with coconut shell, (c) sand filtration with rice husk and (d) sand filtration with rice husk and coconut shell.

\section{Results and discussion}

The wet market waste water was collected at the final discharge of the premise before it being treated with the four types of sand filtrations. Then, the filtered waste water were analysed based on six parameters and compared with the Standard B of Malaysia Environmental Quality (Sewage) Regulations 2009 [5]. The WQI of each effluent of sand filtration is also calculated.

The concentrations of BOD, COD, SS and AN recorded by the effluent of wet market before and after being treated by four types of sand filters is shown in Fig. 2. The results of these parameters are then compared with the Malaysia's regulation.

The result shows that high BOD level is detected before the treatment is applied with $137.07 \mathrm{mg} / \mathrm{L}$ while the lowest is recorded from the sand filter added with rice husk which is $18.97 \mathrm{mg} / \mathrm{L}$. This indicates that more than $80 \%$ of organic matter is removed. Besides that, the result also shows that only two types of sand filters are comply with the Standard B (50 $\mathrm{mg} / \mathrm{L}$ ) which are sand filter added with rice husk and sand filter added with both activated 
carbons. This suggests that the addition of activated carbon in the sand filter composition may reduce the pollutant in the water sample.

High BOD level in water sample has course a threat to the aquatic environment since it reduces the dissolved oxygen concentration to the levels that affect aquatic organisms [6]. This is due to the fact that oxygen is used by microorganisms to oxidize the organic matter to stable inorganic form [7].

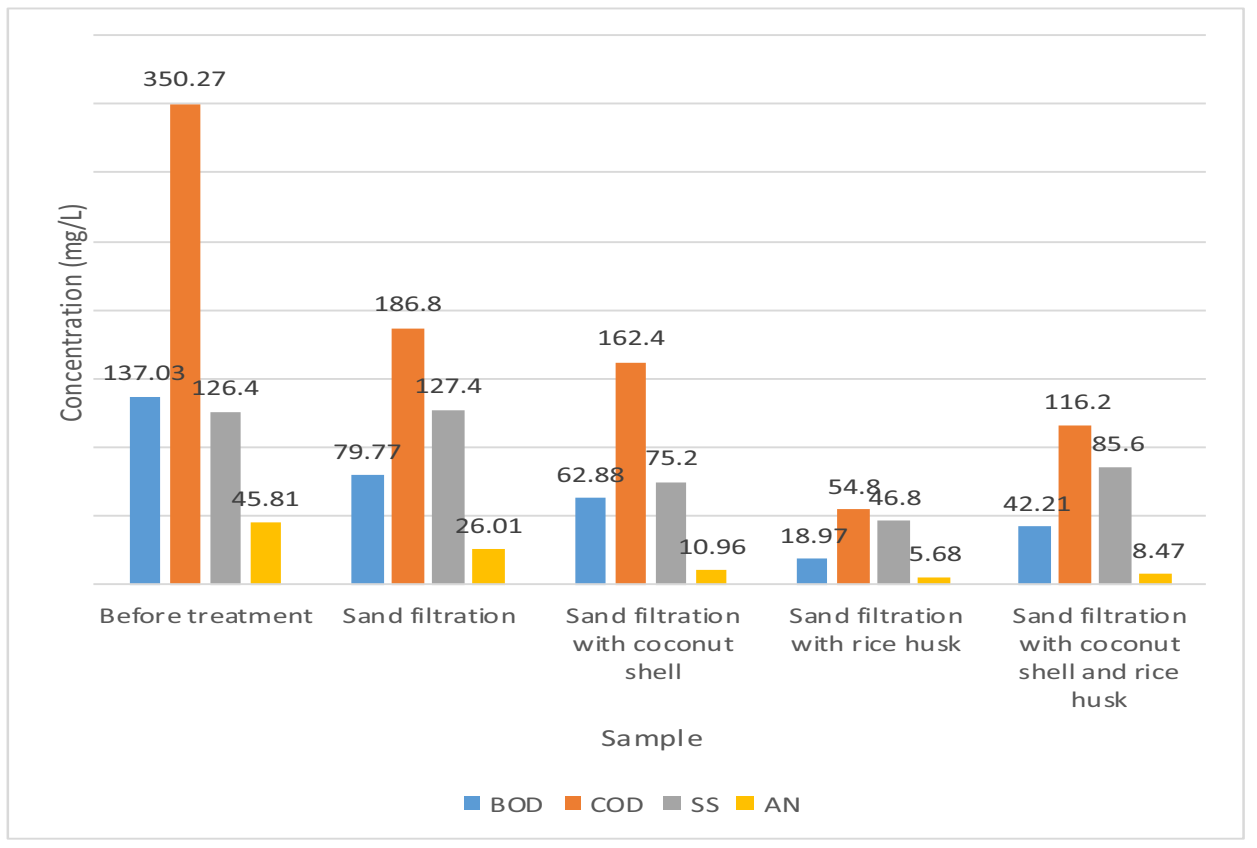

Fig. 2. Concentration of BOD, COD, SS and AN recorded by the wet market waste water before and after treatment with sand filters.

COD is the amount of oxygen required to chemically oxidize organic and inorganic matter. COD gives an estimation of the amount of organic and inorganic matter present. In Fig. 2, it shows that high level of COD recorded before the water sample is treated with $350.27 \mathrm{mg} / \mathrm{L}$. On the other hand, all the water samples that gone through the treatments have shown a good finding where the COD concentrations recorded are lower than the Standard B (200 mg/L), ranging from 54.8 to $186.8 \mathrm{mg} / \mathrm{L}$. This indicates that all types of sand filtrations tested in this study have a potential in removing organic and inorganic matters in the water sample with the higest percentage reduction of $84 \%$.

Further analysis was carried out by examined the level of suspended solids in the water sample before and after the treatment with sand filters. According to Standard B of Malaysia Environmental Quality (Sewage) Regulations 2009, the limits of SS is not more than $100 \mathrm{mg} / \mathrm{L}$. Refering to the Fig. 2, the results show that the water samples are high with SS before the treatment as well as treated with the sand filter. However, the SS concentrations recorded by sand filtrations added with activated carbon have reduced the pollutants in the effluent with the lowest concentration of $46.8 \mathrm{mg} / \mathrm{L}$, indicating of more than $60 \%$ reduction. Excessive SS in the water sample may cause the recieving water to lose its stability in suppoting the diversity of aquatic life. It will abdsorb heat from the sun thus increase the water temperature and lower the levels of dissolved oxygen [8].

The concentrations of AN in the water sample before and after the treatment are shown in Fig. 2. The result shows that the level of AN are ranging from $5.68 \mathrm{mg} / \mathrm{L}$ up to 45.81 
$\mathrm{mg} / \mathrm{L}$ with the lowest and the highest AN concentrations are recorded by sand filter added with rice husk and before the water sample is treated, respectively. Although high percentage reduction is recorded with $87.6 \%$, this concentrations are still not comply with the limit set up by the Malaysian law which is $5 \mathrm{mg} / \mathrm{L}$. AN is very soluble in the water. High level of AN contributes to oxygen demand and nutrient loading of the water bodies, promoting toxic algal blooms and leading to a destablised aquatic ecosystem [9].

The $\mathrm{pH}$ of the water sample is recorded in the study before and after sand filter treatment is shown in Fig. 3. The result shows that the highest $\mathrm{pH}$ is 6.83 which recorded by sand filtration while the lowest is recorded by sand filtration added with both activated carbons with 6.38. Overall, it reveals that the water sample is slightly acidic. Based on the Standard B of Malaysia Environmental Quality (Sewage) Regulations 2009, all the water samples are comply with the limit (5.5-9.0). According to Morrison et al. [10], high pH values could alter the toxicity of other pollutants while low $\mathrm{pH}$ values may affect aquatic life and impair recreational uses of water.

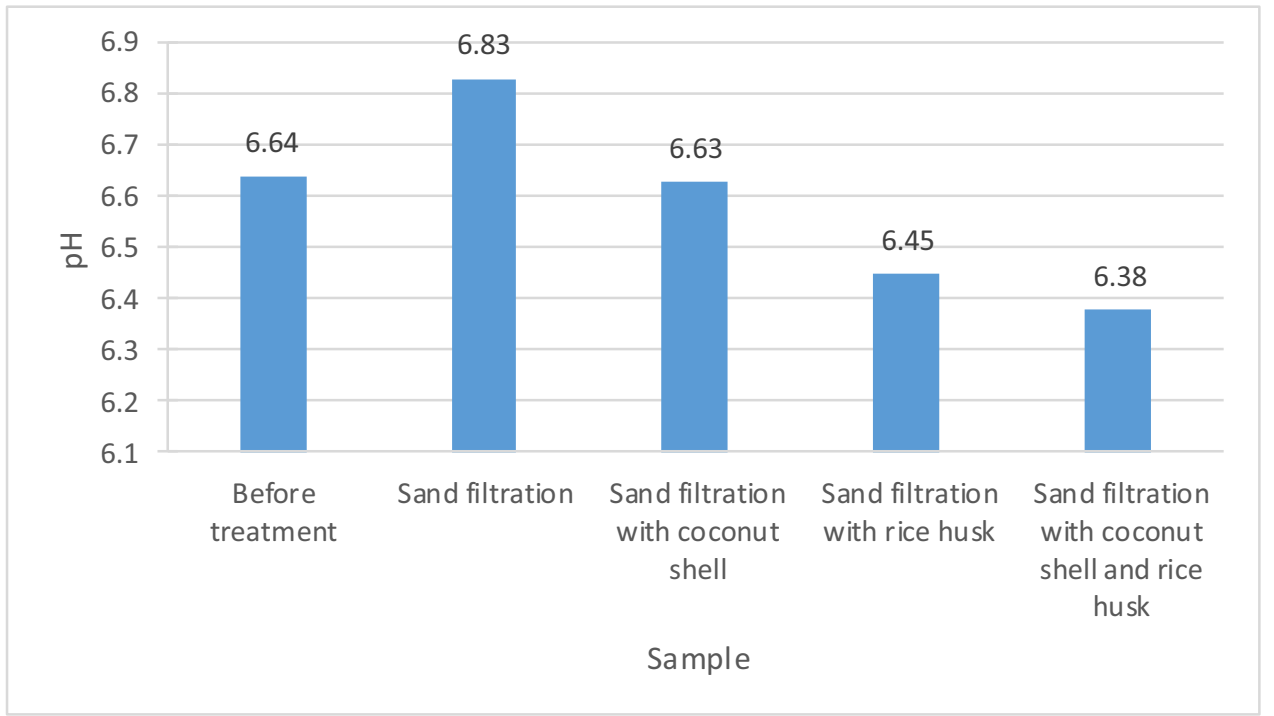

Fig. 3. $\mathrm{pH}$ of the water sample before and after treatment with four types of sand filters.

Fig. 4 shows the level of turbidity of the water samples recorded during the study period. It shows that high turbidity is recorded before the sample is treated with $41.68 \mathrm{NTU}$ while the lowest is recorded by sand filter added with rice husk which recorded 11.12 NTU. Generally, all the effluents collected from sand filters are low which is less than 16 NTU, showing that more than $70 \%$ are reduced. As said by Ntengwe [11], turbidity is caused by the presence of suspended matter, organic particles, plankton and other microscopic organisms. 


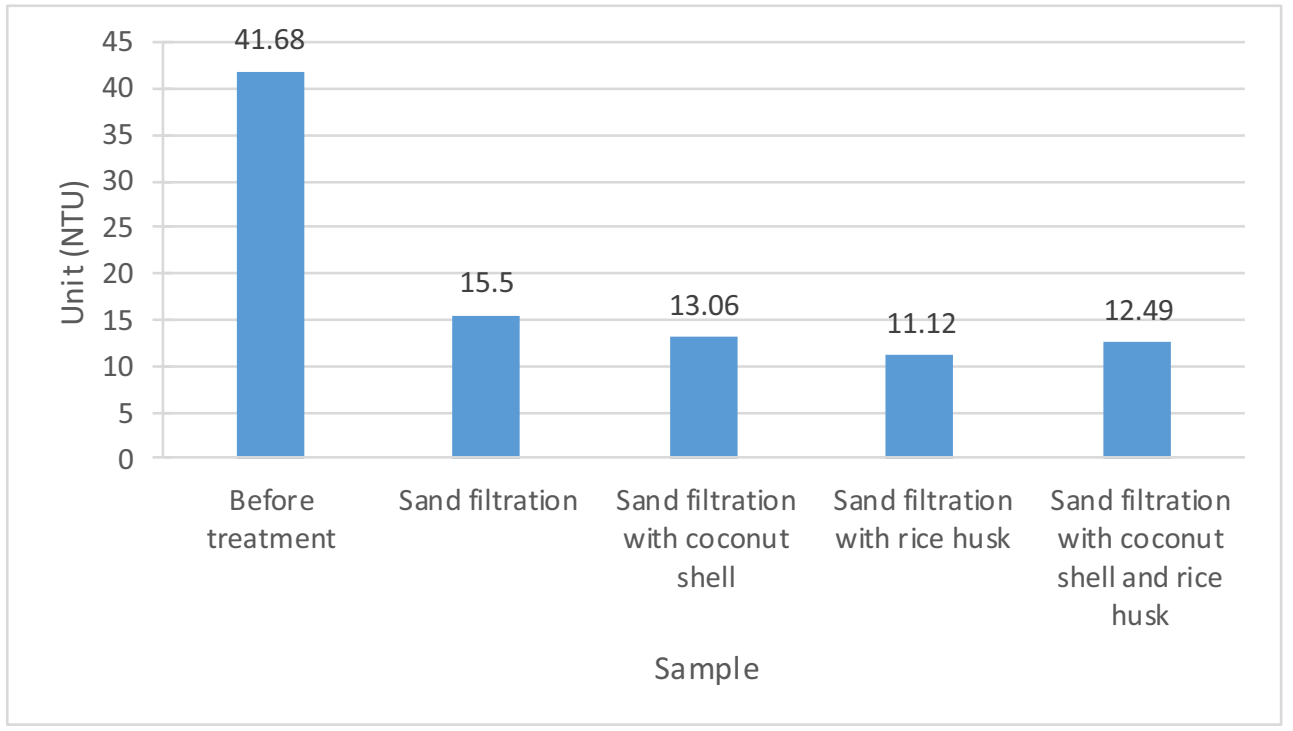

Fig. 4. The turbidity of water sample before and after sand filters treatment.

Water quality index of the water samples are also calculated in this study. Fig. 5 lists the WQI recorded by water samples before and after sand filters treatment. Overall, the result shows that only sand filtrations with rice husk falls in Class IV (31.0-51.9) which is suitable for irrigation purpose only while others fall in Class V (less than 31.0) which is not suitable for any activities. High WQI recorded by sand filter added with rice husk may be due the pores produced during activation that trapped more pollutants of the water thus filtered more efficiently. According to Kalderis et al. [12], the relative surface area $\left(S_{B E T}\right)$ for rice husk was up to $750 \mathrm{~m}^{2} / \mathrm{g}$ while for coconut shell, the relative surface area was 546 $\mathrm{m}^{2} / \mathrm{g}[13]$. Hence, it gives a better result compared to the other samples.

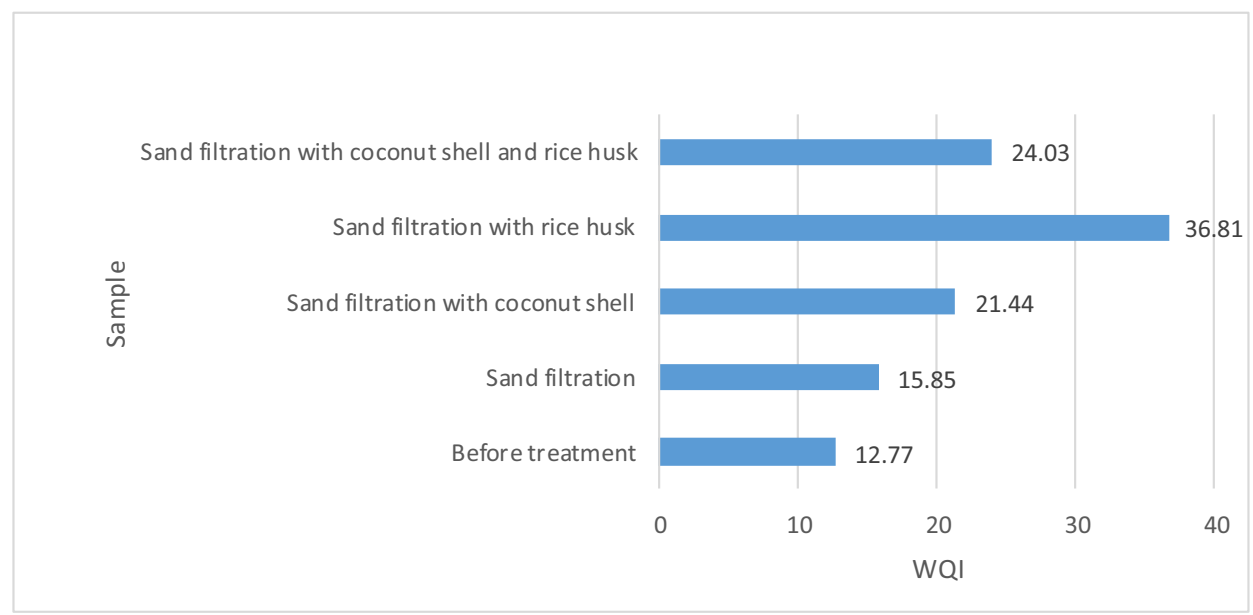

Fig. 5. Water quality index of wet market waste water before and after treatment with four types of sand filters. 


\section{Conclusions}

This study shows that wet market waste water is high with BOD, COD, AN and SS which exceed the limit that set up by Malaysia authority. Therefore, four types of sand filters are constructed in order to treat the waste water produced. There are four types of sand filters examined in this study which one is conventional sand filter while the rest is added with activated carbon. Based on laboratory tests, the modified sand filter that added with rice husk is better than sand filtration added with coconut shell or a combination of both activated carbon. The results show that better performance in eliminating the concentration of the parameters tested is by sand filters added with rice husk where most results are comply to Standard B of Malaysia Environmental Quality (Sewage) Regulations 2009 such as the concentration of BOD, COD, SS, and $\mathrm{pH}$. Besides that, this study also reveals that sand filtration added with activated carbon shows a potential in eliminating the concentration of some parameters compared to the conventional sand filters. Therefore, the addition of activated carbon in the filter can be one of the alternative for the treatment of waste water wet market.

\section{References}

1. Idris, W.N.W. Azmin, M.A.M. Soom, A.A. Mamun, $I^{\text {st }}$ International Conferences on Managing Rivers in The $21^{\text {st }}$ Century: Issue and Challenges (2004)

2. R. Seswoya, A.M.M. Daud, Z.M. Ali, Z.D.M. Basri, R.N.R. Yunus, The first attempt of chicken wastewater treatment using sand filtration (2010)

3. J. Xi, K.M. Mancl, O.H. Touvinen, Proceedings of the 8th International Symposium on Agricultural and Food Proceesing Waste., St. Josepth, MI (2000)

4. American Public Health Association, Standard Methods for the Examination of Water and Wastewater, supplement (American Public Health Association, Washington D.C, 2000)

5. Legal Research Board (LRB), Environmental Quality Act 1974 (ACT 127) (Regulations, Rules and Orders, International Law Book Services, Petaling Jaya, Selangor, Malaysia, 2013)

6. S.K. Garg, Environmental Engineering, 2, 228 (2006)

7. W. Viessman, J.M. Hammer (Harper Collins, New York, 2000)

8. S.H. Peavy, D.R. Rowe, G. Tchobanoglous, Environmental Enginnering (McGraw Hill, New York, 1985)

9. E.O. Igbinosa, A.I. Okoh, Int. J. Environ. Sci. Technol., 6, 175 (2009)

10. G. Morrison, O.S. Fatoki, L. Persson, A. Ekberg, Water SA, 27(4), 475 (2001)

11. F.W. Ntengwe, Phys. Chem. Earth, 31, 832 (2006)

12. D. Kalderis, S. Bethanis, P. Paraskeva, E. Diamadopoulos, Bioresource Technol., 99, 6809 (2008)

13. E.Y. Yazici, H. Devici, I. Alp, T. Yilmaz, O. Celep, Survival and Sustainability: Environmental Concerns in the $21^{\text {st }}$ Century (Springer-Verlag Berlin Heidelberg, 2001) 